\title{
Verrucous Lesion
}

National Cancer Institute

\section{Source}

National Cancer Institute. Verrucous Lesion. NCI Thesaurus. Code C5028.

A papillomavirus related epithelial overg rowth. It can be located anywhere on the body though when it involves the perineal region it is generally referred to as condyloma acuminata. 